\title{
Functional Quality and Colour Attributes of Two High-Lycopene Tomato Breeding Lines Grown under Greenhouse Conditions
}

\author{
Riadh Ilahy $^{*}$, Mohammed Wasim Siddiqui' ${ }^{2}$ Imen Tlili², Gabriella Piro ${ }^{3}$, \\ Marcello Salvatore Lenucci $^{3}$, Chafik Hdider ${ }^{1}$
}

${ }^{1}$ Laboratory of Horticulture, National Agricultural Research Institute of Tunisia, Tunis, Rue Hédi Karray 2049 Ariana, Tunisia

${ }^{2}$ Department of Food Science and Postharvest Technology, Bihar Agricultural University, Sabour, Bhagalpur, Bihar 813210, India ${ }^{3}$ Dipartimento di Scienze e Tecnologie Biologiche ed Ambientali, Università del Salento, Via Prov.le Lecce-Monteroni, 73100 Lecce, Italy A R T I C L E I N F O

Article history:

Received 14 December 2015

Accepted 11 February 2016

Available online, ISSN: 2148-127X

\section{Keywords:}

High-lycopene tomato

Carotenoids

Flavonoids

Greenhouse

Hydrophilic antioxidant

Lipophilic antioxidant

${ }^{*}$ Corresponding Author:

E-mail: riadh.ilahy@iresa.agrinet.tn

A B S T R A C T

This study investigates the antioxidant components (total carotenoids, lycopene, $\beta$ carotene, total phenols, flavonoids, ascorbic acid and total vitamin C) as well as the hydrophilic and lipophilic antioxidant activities (HAA and LAA) of tomato genotypes consisting of one ordinary cultivar Rio Grande and the two high-lycopene breeding lines HLT-F71 and HLT-F72. The correlation of nutritional value to $\mathrm{L}^{*}, \mathrm{a}^{*}, \mathrm{~b}^{*}$ colour indexes and $\mathrm{a}^{*} / \mathrm{b}^{*}$ ratio was also investigated in whole and fresh cut tomato fruits. Except for $\beta$ carotene content, significant differences were found among cultivars for antioxidants. The berries of both HLT-lines recorded higher antioxidant contents, HAA and LAA (TEAC and FRAP assays) than Rio Grande. Under controlled conditions, HLT-F72 reached the highest levels of total carotenoids (165.5 mg $\beta$-ca Eq per $\mathrm{kg} \mathrm{fw}$ ), lycopene (150.1 mg per $\mathrm{kg} \mathrm{fw}$ ) and total phenolics (549.7 mg GAE per $\mathrm{kg} \mathrm{fw}$ ). However, HLT-F72 exhibited the highest levels of ascorbic acid (193.3 $\mathrm{mg}$ per $\mathrm{kg} \mathrm{fw})$, total vitamin $\mathrm{C}(271.6 \mathrm{mg}$ per $\mathrm{kg}$ fw) and flavonoids (450.5 mg RE per kg fw). Line HLT-F71 showed the highest HAA $(148.0 \mu \mathrm{M}$ Trolox per $100 \mathrm{~g}$ fw and $4.2 \mathrm{mM}$ FRAP per $\mathrm{g} f \mathrm{w})$ and LAA values $(258.5 \mu \mathrm{M}$ Trolox per $100 \mathrm{~g}$ fw and $3.2 \mathrm{mM}$ FRAP per $\mathrm{g}$ fw respectively). Colour readings in red ripe fresh cut tomato berries particularly $\mathrm{a}^{*}, \mathrm{~b}^{*}$ and the ratio $\mathrm{a}^{*} / \mathrm{b}^{*}$ could represent an indicator not only for lycopene but also for other phytochemicals and resulting antioxidant activities. HLT-Lines may serve as a starting point for the development of semi-determinate growth habit tomato cultivars with higher functional quality.

\section{Introduction}

Tomato (Solanum lycopersicum L.) berries, commonly consumed in the Mediterranean diet, offer a diverse mixture of nutrients that are essential for human nutrition and contribute to the promotion of good health and wellbeing. Increased consumption of fresh or processed tomato products (canned tomatoes, sauce, juice, ketchup, soup, etc.) is directly associated with a reduced risk of contracting several widespread human pathologies, including cardiovascular diseases, prostate, lung and stomach cancers, osteoporosis and UV radiations associated skin disorders (Erdman et al., 2009; Fernández-Garcia 2014a, b; Qu et al., 2013; Soares et al., 2014;). Flavonoids, phenols, ascorbic acid (vitamin C), tocochromanols (Vitamin E) and carotenoids, mainly lycopene, are important bioactive molecules of ripe tomato fruits (Ilahy et al., 2016; Lenucci et al., 2006). These compounds synergizes to exert a positive effects on human health through oxidative and still not fully understood non-oxidative mechanisms (Erdman et al., 2009; Fernández-García 2014a, b; Soares et al., 2014;
Takashima et al., 2012;). Consequently tomato fruits are increasingly considered as "functional food" (Ilahy et al., 2011a, b; Ilahy et al., 2015; Ilahy et al., 2016; Siddiqui et al., 2014) .

Fruit color is a quality characteristic that has received intensive attention by fresh-market and processing tomato industries as well as consumers (Kaur et al., 2013). The final color in tomato fruit is conditioned by the total amount and proportion of different carotenoids mainly lycopene. Lycopene represents $90 \%$ of the total pigments in ripe fruits (Ilahy et al., 2011a, b; Ilahy et al., 2015). In vitro studies revealed that lycopene is 2 -fold and 10 -fold more effective in quenching reactive oxygen species than $\beta$-carotene and $\alpha$-tocopherol, respectively (Di Mascio et al., 1989) and has the highest Trolox Equivalent Antioxidant Capacity (TEAC) value among all carotenoids (Rice-Evans et al., 1997). This stressed the need for improving lycopene levels in tomato fruits (Bramley 2000; Kaur et al., 2013; Siddiqui et al., 2014), leading to the selection, by conventional plant breeding 
programs, of a large number of new tomato lines with increased levels of lycopene (high-lycopene tomatoes) to satisfy the ever-growing demand of growers, processors and consumers for functional food (Ilahy et al., 2009; Ilahy et al., 2016).

Hydrophilic and lipophilic antioxidant content and antioxidant activity in tomatoes can be determined accurately by spectorphotometric or HPLC measurements of tissue extract (Ilahy et al., 2016; Lenucci et al., 2006) However, this procedure is time-consuming, destructive and use hazardous solvents. In addition, breeding for improved nutritional quality is dependent upon the availability of simple, non-destructive reproducible and accurate methodologies to quickly quantify/estimate not only hydrophilic and lipophilic antioxidant compounds but also their hydrophilic and lipophilic antioxidant activity in a large sample size.

The measurement of fruit colour attributes was used in the last decades to estimate lycopene content in tomato fruits (Arias et al., 2000; D’Souza et al., 1992; Ilahy et al., 2007; Kaur et al., 2013) regardless the other classes of phytochemicals present at high levels in tomato fruits as well as their resulting antioxidant activity. Besides their considerable level of lycopene high-lycopene tomato cultivars accumulate high levels of various valuable hydrophilic and lipophilic antioxidants such as, total phenolics, flavonoids and ascorbic acid (Hdider et al., 2013; Ilahy et al., 2011a, b, 2016; Lenucci et al., 2006;). Therefore, a rapid method that accurately estimates not only lycopene but also other classes of antioxidant in tomato berries is required. To our knowledge there are no reports about the colour attributes as well as their correlations to the phytochemical content in highlycopene tomato lines.

The functional quality of tomato is strongly influenced by environmental factors and genetics. It is widely recognized that the functional quality of greenhouse tomato fruit is lower with respect to those grown in open field (Toor and Savage 2005). The performance of highlycopene tomato varieties under greenhouse conditions is poorly studied. Previously, Andrews et al. (2004) conducted a study of the ( $h p)$ tomato under greenhouse conditions. However, the authors were more focused on the antioxidant defense enzymatic system in tomato exocarp rather than assessing the functional quality of tomato fruit. Although high-lycopene tomato breeding lines used in this study were determinate habit varieties it is important to assess the performance of newly developed high-lycopene tomato cultivars under changing global climactic patterns to ensure consistent functional quality.

Therefore, the aim of this work was to assess the phytochemical composition (total carotenoids, lycopene, phenols, flavonoids, AsA, total vitamin C), the antioxidant activity (both hydrophilic and lipophilic) measured using the TEAC and the FRAP assays in highlycopene tomato advanced breeding lines (HLT-F71 and HLT-F72) and the ordinary (Rio Grande) tomato cultivar grown simultaneously under greenhouse conditions and to examine their correlations to color attributes.

\section{Materials and methods}

\section{Plant Culture}

The experiments were carried out in a greenhouse at the National Agricultural Research Institute of Tunisia in Northern Tunisia during the 2014-2015 growing season (September-March). Three tomato cultivars were used: two high-lycopene tomato advanced breeding lines with the assigned names 'HLT-F71' and 'HLT-F72' (F7 generation), selected by the National Agricultural Research Institute of Tunisia, and the open-pollinated cultivar Rio Grande (Petoseed, Saticoy, CA, USA) commonly grown in Tunisia. The high-lycopene tomato cultivars HLT-F71 and HLT-F72 have been developed through conventional plant-breeding techniques taking into account the careful selection of the high-lycopene trait (Ilahy et al., 2009; Ilahy et al., 2016). This important commercial trait is commonly due to the presence of light-responsive high-pigment (hp) mutations such as hp1 , hp- $1^{\mathrm{w}}, \mathrm{hp}-2, \mathrm{hp}-2^{\mathrm{j}}$, hp- $2^{\mathrm{dg}}$, and hp-3, which lead to an increase of carotenoid and flavonoid biosynthesis (Galpaz et al., 2008; Wann 1997;). Sowing was carried out on 3 September 2014 in plug-seedling trays. One month-old tomato seedlings were transplanted in a greenhouse with a spacing of approximately $0.4 \mathrm{~m}$ within the row and $1.5 \mathrm{~m}$ between rows, matching a density of about 16,667 plants per ha and grown to maturity. The experimental design was a randomised complete block with three blocks (replicates). Irrigation was applied using a drip method with $4 \mathrm{~L} \mathrm{~h}^{-1}$ drippers placed at $0.4 \mathrm{~m}$ intervals along the irrigation line. Standard agronomical techniques were used for drip irrigation, plant nutrition and pathogen prevention as described by Ilahy et al. (2011a).

\section{Fruit Sampling}

Tomato fruits were hand harvested randomly from the rows and from the middle of the plant of each block at the red-ripe stage and delivered quickly to the laboratory. Fully ripe healthy tomato berries, homogeneous for intense red-colour and size and blemish free were visually selected (at least $2 \mathrm{~kg}$ for each cultivar and for each block). Tomato fruits were cut into small pieces and homogenized in a mixer (Waring Laboratory \& Science, Torrington, CT, US). The obtained juice was frozen at $20^{\circ} \mathrm{C}$ and used to determine total carotenoids, lycopene, total phenols, total flavonoids, AsA, total vitammin $\mathrm{C}$ contents as well as the HAA and LAA within less than one week, in order to minimize the depletion of nutrients that inevitably occurs even during frozen homogenate storage (Philips et al., 2010).

\section{Analytical Procedures}

Carpometric characteristics: Soluble solid content of the tested cultivars was expressed by the Brix of fresh juice. The measurement was taken by placing a drop of filtered juice on the prism of a digital refractometer with automatic temperature compensation (Atago PR-100 NSG Precision Cells, Inc, Framing dale, NY). Titrable acidity was estimated after titration at a $\mathrm{pH}$ of 8.1 with a sodium hydroxide solution $(0.1 \mathrm{M})$ and results were expressed as 
percentage of citric acid. The CIELAB L* (lightness), $a^{*}$ (redness) and $\mathrm{b}^{*}$ (yellowness) readings were measured on the whole (skin) and fresh cut (pulp) tomato fruit using a Minolta Chroma meter (CR-400, Minolta corp.) from which, the ratio a $/ \mathrm{b}^{*}$ was calculated.

Determination of total carotenoids, lycopene and $\beta$ carotene content: Total carotenoids and lycopene extraction and determination were conducted as described by (Lee 2001) and Fish et al. (2002), respectively. The method uses a mixture of hexane/ethanol/ acetone (2/1/1 by vol.) containing $0.05 \%$ butylated hydroxytoluene (BHT). During the extraction process, some precautions were taken, like working in a reduced luminosity room and wrapping glass materials in aluminium foil to avoid lycopene loss by photooxidation. For total carotenoid and lycopene quantification, the absorbance of the hexane extract was read at 450 and $503 \mathrm{~nm}$ respectively using a Cecil Instruments Ltd., Cambridge, UK. Total carotenoids were expressed as $\mathrm{mg} \beta$-carotene equivalents $/ \mathrm{kg}$ of $\mathrm{fw}$ (mg b-CaE/kg fw). Lycopene molar extinction e $=17.2 *$ $10^{4} \mathrm{M}^{-1} \mathrm{~cm}^{-1}$ in $\mathrm{n}$-hexane was used for lycopene content determination. $\beta$-carotene content was determined according to Nagata and Yamashita (1992) Lycopene and $\beta$-carotene contents were expressed as $\mathrm{mg} / \mathrm{kg}$ fw.

Determination of total phenolics content: Total phenols were extracted as described by MartínezValverde et al. (2002) on triplicate independent aliquots $(0.3 \mathrm{~g})$ of each fraction. Briefly, $5 \mathrm{~mL}$ of $80 \%$ aqueous methanol and $50 \mu \mathrm{L}$ of $37 \% \mathrm{HCl}$ were added to each sample. The extraction was performed at $4{ }^{\circ} \mathrm{C}$, for $2 \mathrm{~h}$, under constant shaking $(300 \mathrm{rpm})$. Samples were centrifuged at $10000 \mathrm{~g}$ for $15 \mathrm{~min}$. The total phenols assay was performed by using the Folin-Ciocalteu reagent as described by Spanos and Wrolstad (1990) on triplicate 50 $\mu \mathrm{L}$ aliquots of the supernatant. The absorbance was read at $750 \mathrm{~nm}$ using a Cecil BioQuest CE 2501 spectrophotometer (Cecil Instruments Ltd., Cambridge, UK). The linear reading of the standard curve was from 0 to $300 \mu \mathrm{g}$ gallic acid equivalent $/ \mathrm{mL}$. Results were expressed in $\mathrm{mg}$ of gallic acid equivalent (GAE)/kg fwSince sugars may interfere with the total phenolic content in sample containing high sugar levels, total phenolic contents were corrected for sugar interference, according to Asami et al., (2003) using the same methodology for total phenolics quantification.

Determination of total flavonoid content: The total flavonoid content was determined as described by Zhishen et al. (1999) on triplicate independent aliquots $(0.3 \mathrm{~g})$ of each fraction. The resulting methanolic extract (50 $\mu \mathrm{L}$ aliquots) was used for determination of total flavonoids. Samples were diluted with distilled water to a final volume of $0.5 \mathrm{~mL}$, and $30 \mu \mathrm{L}$ of $5 \% \mathrm{NaNO}_{2}$ was added. After $5 \mathrm{~min}, 60 \mu \mathrm{L}$ of $10 \% \mathrm{AlCl}_{3}$ was added and finally $200 \mu \mathrm{L}$ of $1 \mathrm{M} \mathrm{NaOH}$ was added after $6 \mathrm{~min}$. The absorbance was read at $510 \mathrm{~nm}$ in a Cecil BioQuest CE 2501 spectrophotometer (Cecil Instruments Ltd., Cambridge, UK). The linear reading of the standard curve was from 0 to $250 \mu \mathrm{g}$ rutin/mL and total flavonoid content was expressed as $\mathrm{mg}$ of rutin equivalent $(\mathrm{RE}) / \mathrm{kg} \mathrm{fw}$.
Determination of ascorbic acid and dehydroascorbic acid content: Ascorbic acid (AsA) and dehydroascorbic acid (DHA) contents were determined as reported by Kampfenkel et al. (1995) on triplicate samples of the homogenate juice $(0.1 \mathrm{~g})$. AsA and DHA were extracted by using $6 \%$ metaphosphoric acid and detected at $525 \mathrm{~nm}$ in Cecil BioQuest CE 2501 spectrophotometer (Cecil Instruments Ltd., Cambridge, UK). The linear reading of the standard curve was from 0 to $700 \mathrm{mmol}$ AsA. The assay used for the determination of AsA and DHA is based on the reduction of $\mathrm{Fe}^{3+}$ to $\mathrm{Fe}^{2+}$ by $\mathrm{AsA}$ and spectrophotometric detection of $\mathrm{Fe}^{2+}$ complexed with 2,20-dipyridyl. DHA is reduced to AsA by preincubation of the sample with dithiothreitol (DTT). Subsequently the excess DTT is removed with N-ethylmaleimide (NEM) and total AsA is determined by the 2, 20-dipyridyl method. The concentration of DHA is then calculated from the difference of total AsA and AsA (without pretreatment with DTT). Vitamin C content is the sum of both (AsA + DHA) contents.

Antioxidant activity: We used different solvents for the preparation of the hydrophilic and lipophilic fractions, in the TEAC (methanol and acetone) and FRAP (methanol and hexane) determinations according to Benzie and Strain (1996) for FRAP assay and Miller and Rice-Evans (1997) for the TEAC assay. The used solvents are the most used ones for the extraction of hydrophilic and lipophilic antioxidants in the FRAP and TEAC assays according to the literature. The advantages of the ABTS and FRAP assays are that both techniques require simple equipment and a spectrophotometer. Besides, extracts reacts rapidly with ABTS $(2 \mathrm{~h})$ or ferric ions (30 min) compared for example to other assay like DPPH (24 h) (Thaipong et al., 2006).

Trolox equivalent antioxidant capacity (TEAC) assay: The measurement of the hydrophilic and lipophilic antioxidant actvity (HAA and LAA, respectively) was performed using the TEAC assay. The antioxidant activity was measured using the ABTS decoloration method (Pellegrini et al., 2007). The TEAC assay is standardly used for antioxidant activity assessement of fruit and vegetables, its numerous advantages consist in reproducibility, simplicity, and a good estimate of the antioxidant activity of pure compounds and complex matrices (Thaipong et al., 2006; Pellegrini et al., 2007). Hydrophilic and lipophilic antioxidants were extracted from $0.3 \mathrm{~g}$ of each fruit fraction (three independent replicates) with $50 \%$ methanol or $50 \%$ acetone, respectively, at $4^{\circ} \mathrm{C}$ under constant shaking (300 rpm) for $12 \mathrm{~h}$. Samples were centrifuged at $10000 \mathrm{~g}$ for $7 \mathrm{~min}$. Supernatants were recovered and used for antioxidant activity measurements. The antioxidant activities were measured at $734 \mathrm{~nm}$ in a Cecil BioQuest CE 2501 spectrophotometer (Cecil Instruments Ltd., Cambridge, UK). Two different calibration curves were constructed using freshly prepared trolox solutions for HAA and LAA determinations. The linear reading of the standard curves was from 0 to $16 \mu \mathrm{M}$ Trolox for both HAA and LAA. Values were expressed as $\mu \mathrm{M}$ of Trolox/100 $\mathrm{g}$ of fw. 
Ferric reducing antioxidant power (FRAP) assay: Hydrophilic and lipophilic antioxidants were extracted from $0.3 \mathrm{~g}$ of homogenate (three replicates) with absolute methanol or hexane at $4^{\circ} \mathrm{C}$ under constant shaking $(300$ rpm) overnight. Samples were centrifuged at 10,000 g. The supernatants were used for antioxidant activity measurement. Antioxidant activity was measured in both hydrophilic and lipophilic fractions using the FRAP assay method (Benzie and Strain 1996). $50 \mathrm{~mL}$ of hydrophilic or lipophilic tomato extract was added to $1.5 \mathrm{~mL}$ of FRAP reagent $[1 \mathrm{mM}$ 2,4,6-tripiridyl-2-triazine (TPTZ) and 20 $\mathrm{mM}$ ferric chloride in $0.25 \mathrm{M}$ sodium acetate buffer, $\mathrm{pH}$ 3.6] and mixed thoroughly. After $4 \mathrm{~min}$ at $48^{\circ} \mathrm{C}$, absorbance at $593 \mathrm{~nm}$ was read against a blank of water. A calibration curve was prepared using freshly prepared ammonium ferrous sulfate. The linear reading of the standard curve was from 0 to $1200 \mathrm{mM}$ FRAP. Values were obtained from three replicates as $\mathrm{mM} \mathrm{FRAP/g}$ of tomato fw (mM FRAP/g fw).

\section{Statistical Analysis}

The variations in the nutritional properties of the redripe berries of the ordinary Rio Grande tomato cultivar and the two high-lycopene tomato advanced breeding lines (HLT-F71 and HLT-F72) were assessed by analysis of variance (ANOVA). When a significant difference was detected, means were compared using the least significant difference (LSD) test $(\mathrm{P}<0.05)$. All statistical comparisons were performed using SAS Version 6.1 software (SAS Institute, Cary, NC, USA). Correlations were performed using Pearson's correlation coefficient ( $\mathrm{r}$ $\pm \mathrm{SE}$ ).

\section{Results and discussion}

\section{Carpometric Characteristics}

Colour is one of the most important quality attribute of fruits and vegetables. It is the primary factor that consumer evaluate before any fresh produce purchase (Brandt et al., 2006; Fernàndez-Ruiz et al., 2010). When external colour readings were considered (Table 1), no significant differences $(\mathrm{P}>0.05)$ were found in $\mathrm{L}^{*}$ (lightness), $\mathrm{a}^{*}$ (redness), $\mathrm{b}^{*}$ (yellowness) and the ratio $\mathrm{a}^{*} / \mathrm{b}^{*}$ determined in tomato berries. This was expected, since based on the external appearance, the separation between high-lycopene and ordinary tomato berries is rather difficult. However, this operation was easier using fresh-cut tomato berries where their pulp had intense red colour compared to light red colour in Rio Grande. In this context, the colour indexes $a^{*}, b^{*}$ and the ratio $a^{*} / b^{*}$ varied significantly in fresh-cut tomato berries $(\mathrm{P}<0.05)$. The redness $\mathrm{a}^{*}$ increased in fresh cut HLT-F71 berries with respect to external redness values and ranged from 20.52 in Rio Grande to 32.35 in HLT-F71. The yellowness $b^{*}$ values decreased in all the cultivars compared to whole tomato berries and ranged from 23.59 in Rio Grande to 28.34 in HLT-F71. This is expected since tomato skin is yellow whereas tomato pulp is red. Regarding the ratio $\mathrm{a}^{*} / \mathrm{b}^{*}$ high-lycopene tomato berries had the highest values (1.14 and 1.18 for HLT-F71 and HLT-F72 respectively) compared to 0.86 for Rio Grande which confirms that high-lycopene tomato had higher lycopene content with respect to the traditional cv Rio Grande. All the obtained $\mathrm{L}^{*}, \mathrm{a}^{*}, \mathrm{~b}^{*}$ and $\mathrm{a}^{*} / \mathrm{b}^{*}$ values are in accordance with those reported for tomato fruit grown under different geographical areas (Arias et al., 2000; Chandra et al., 2012; D’Souza et al., 1992; Ilahy et al., 2007).

The average fruit weight, soluble solids and titratable acidity varied significantly between the studied tomato cultivars $(\mathrm{P}<0.05)$. Average fruit weight ranged from 91.7 $\mathrm{g}$ in HLT-F71 to $104.3 \mathrm{~g}$ in HLT-F72. Soluble solids ranged from $5.8^{\circ}$ Brix in Rio Grande to 6.7 Brix in HLTF71. Soluble solids and average fruit weight were similar to previous study on field grown high-lycopene tomato (Ilahy et al., 2011a).

\section{Carotenoid Content}

The amounts of total carotenoids, lycopene, $\beta$ carotene, total phenolics, flavonoids, ascorbic acid and total vitamin $\mathrm{C}$ in ordinary and high-lycopene tomato cultivars are reported in Table 2. Except for $\beta$-carotene, total carotenoids and lycopene contents were significantly different among the studied tomato cultivars $(\mathrm{P}<0.05)$. Total carotenoids ranged from $85.7 \mathrm{mg} \beta$-ca $\mathrm{E} / \mathrm{kg}$ fw in $\mathrm{cv}$ Rio Grande to $165.5 \mathrm{mg} \beta$-ca E/kg fw in HLT-F71, whereas lycopene ranged from $74.8 \mathrm{mg} / \mathrm{kg}$ fw in Rio Grande to $150.0 \mathrm{mg} / \mathrm{kg}$ fw in HLT-F71.

Although lycopene represents the most abundant carotenoids in red-ripe tomatoes, approximately from 80 to $90 \%$ of the total carotenoids (Ilahy et al., 2011a, b) we have also determined the $\beta$-carotene content. $\beta$-carotene, an important carotenoid with provitamin A activity, represents $5-7 \%$ of the total carotenoid in tomato fruit (Ilahy et al., 2011b). In this study, $\beta$-carotene content ranged from $3.3 \mathrm{mg} / \mathrm{kg}$ fw in HLT-F72 to $8.7 \mathrm{mg} / \mathrm{kg}$ fw in HLT-F71. Therefore, HLT-F71 tomato berries showed the highest total carotenoids, lycopene and $\beta$-carotene contents when compared to cv Rio Grande. HLT-F71 had $93 \%$ and $100 \%$ higher total carotenoids and lycopene content respectively with respect to Rio Grande. The obtained values are in the range reported recently by Ilahy et al., (2011a, b, 2016,) Lenucci et al., (2006) ranging from 199 to $278 \mathrm{mg} \beta$-ca $\mathrm{E} / \mathrm{kg}$ fw for total carotenoids, from 28 to $893 \mathrm{mg} / \mathrm{kg}$ fw for lycopene and from 5 to 20 $\mathrm{mg} / \mathrm{kg}$ fw for $\beta$-carotene measured in different tomato cultivars grown under open field conditions.

Interestingly, the obtained lycopene values are higher compared to those generally recorded for greenhouse grown tomato cultivars ranging from 6.2 to $62.7 \mathrm{mg} / \mathrm{kg}$ fw (Chandra et al., 2012; Vínha et al., 2014) and higher also than open field grown traditional tomato cultivars from various geographical area ranging from 96.6 to $105.0 \mathrm{mg} / \mathrm{kg}$ fw (Hdider et al., 2013; Ilahy et al., 2011a, b; Ilahy et al., 2016).

Tomato hp mutations are best known to raise not only lycopene levels in red-ripe tomato berries (Ilahy et al., 2016; Levin et al., 2006; Mochizuki and Kamimura 1984; Wann 1997) but also the content of $\beta$-carotene and other plastid-accumulating metabolites (Ilahy et al., 2011b; Lenucci et al., 2006). Therefore, the development of high- 
lycopene tomato cultivars suitable for greenhouse condition will contribute to compensate for the low functional quality generally reported in greenhouse grown tomato cultivars and to improve the consumer intake. The massive accumulation of these valuable compounds can be ascribed to a complex combination of factors comprising a superior biosynthetic and accumulation/sequestration potential of the metabolites in these cultivars than in the traditional cultivars (Lenucci et al., 2012).

\section{Total Phenolics and Total Flavonoid Content}

Significant differences $(\mathrm{P}<0.05)$ were found among cultivars in total phenolics and flavonoids. Total phenolics values ranged from $407.0 \mathrm{mg} \mathrm{GAE} / \mathrm{kg} \mathrm{fw}$ in Rio Grande to $549.7 \mathrm{mg}$ GAE/kg fw in HLT-F71. Flavonoids content ranged from $243.0 \mathrm{mg} \mathrm{RE} / \mathrm{kg} \mathrm{fw}$ in Rio Grande to $450.7 \mathrm{mg}$ RE/kg fw in HLT-F72. HLT-F72 showed therefore the highest and the lowest flavonoid and total phenolic content respectively. HLT-F71 and HLTF72 had 30\% and 85\% higher total phenolics and flavonoid content respectively compared to Rio Grande.

Although, grown under greenhouse conditions, the obtained total phenolics values were in accordance with those of , Hdider et al., (2013), Ilahy et al., ( 2011a, b)and and Ilahy et al., (2016) ranging from 105 to $877 \mathrm{mg}$ $\mathrm{GAE} / \mathrm{kg}$ fw in different high-lycopene tomato cultivars depending on the ripening stage, from 105.8 to $394.5 \mathrm{mg}$ $\mathrm{GAE} / \mathrm{kg}$ fw at the red-ripe stage depending on the cultivar and from 216.1 to $641.8 \mathrm{mg} \mathrm{GAE} / \mathrm{kg}$ fw depending on the fraction. Higher values ranging from 1200 to $1330 \mathrm{mg}$ GAE/kg fw were reported by Lenucci et al. (2006) for red-ripe berries of high-pigment tomato cultivars grown in Southern Italy. Nevertheless, lower values were generally reported for greenhouse grown tomato ranging from 87 to $177 \mathrm{mg} \mathrm{GAE} / \mathrm{kg}$ fw in the pulp of different tomato cultivars from different geographical areas (Chandra and Ramalingam 2011; Chandra et al. 2012; Toor and Savage 2005).

Recently Hdider et al. (2013) and Ilahy et al. (2016, $2011 \mathrm{a}, \mathrm{b})$ reported flavonoid content values ranging from 105.6 to $590.6 \mathrm{mg} \mathrm{GAE} / \mathrm{kg} \mathrm{fw}$ in different high-lycopene tomato cultivars depending on the ripening stage, from 105.6 to $394.5 \mathrm{mg} \mathrm{GAE} / \mathrm{kg} \mathrm{fw}$ at the red-ripe stage depending on the cultivar and from 222 to $783 \mathrm{mg} \mathrm{RE} / \mathrm{kg}$ fw depending on the fraction.

The flavonoid values obtained are much higher when compared to those of the ordinary tomato cultivars Rio Grande and Donald grown under different growing conditions ranging from 120.2 to $133.0 \mathrm{mg} \mathrm{RE} / \mathrm{kg}$ fw.

The high total phenolics and flavonoid content can be ascribed to the high-lycopene trait. In fact, it has been reported that in red-ripe tomato fruits, naturally carrying mutations that increase carotenoid content, such as high pigment (hp-1, hp- $1^{\mathrm{w}}, \mathrm{hp}-2, \mathrm{hp}-2^{\mathrm{j}}$, hp- $2^{\mathrm{dg}}$ ) mutations, were also characterized by a dramatic increase in plastid biogenesis and in the production of other compounds such as flavonoids and vitamin C (Bino et al., 2005; Mochizuki and Kamimura 1984; Mustilli et al., 1999).

\section{Vitamin C Content}

Ascorbic acid and total vitamin $\mathrm{C}$ contents were significantly different among the studied tomato cultivars $(\mathrm{P}<0.05)$. Ascorbic acid content ranged from $91 \mathrm{mg} / \mathrm{kg} \mathrm{fw}$ in Rio Grande to $193.3 \mathrm{mg} / \mathrm{kg}$ fw in HLT-F72. HLT-F72 showed the highest AsA and total vitamin C content. AsA contributed from $41 \%$ to $74 \%$ of the total vitamin $\mathrm{C}$ content. Total vitamin C content ranged from 221.8 $\mathrm{mg} / \mathrm{kg}$ fw in Rio Grande to $271.6 \mathrm{mg} / \mathrm{kg}$ fw in HLT-F72. HLT-F71 had statistically similar total vitamin C to Rio Grande. Compared to Rio Grande, HLT-F72 showed 22\% higher total vitamin $\mathrm{C}$ content. Similar increase in vitamin $\mathrm{C}$ contents was reported for the photomorphogenic tomato mutants (hp-1 and hp-2) by Mochizuki and Kamimura (1984) and Mustilli et al. (1999). Although grown under greenhouse conditions, the amounts of total vitamin $\mathrm{C}$ in high-lycopene tomato berries were similar to previous studies on field-grown hp tomato ranging from 125 to 333 $\mathrm{mg} / \mathrm{kg}$ fw (Lenucci et al., 2006; Ilahy et al., 2011b). While field-grown tomato have higher AsA levels (up to $258 \mathrm{mg} / \mathrm{kg} \mathrm{fw}$ ) compared to those produced under shade $(155 \mathrm{mg} / \mathrm{kg} \mathrm{fw})$ we suggest that the development of highlycopene tomato cultivars for greenhouse could highly improve the vitamin $\mathrm{C}$ content and its intake.

Table 1 Mean value of carpometric characteristics of the studied tomato cultivars

\begin{tabular}{|c|c|c|c|}
\hline Attributes & HLT-F71 & HLT-F72 & Rio Grande \\
\hline$\left(\mathrm{L}^{*}\right)_{\text {whole }}$ & $41.3 \pm 0.7^{\mathrm{a}}$ & $41.2 \pm 0.8^{\mathrm{a}}$ & $39.6 \pm 0.3^{\mathrm{a}}$ \\
\hline$\left(\mathrm{a}^{*}\right)_{\text {whole }}$ & $27.8 \pm 0.9^{\mathrm{a}}$ & $26.1 \pm 1.1^{\mathrm{a}}$ & $26.4 \pm 0.4^{\mathrm{a}}$ \\
\hline$\left(b^{*}\right)_{\text {whole }}$ & $29.2 \pm 1.5^{\mathrm{a}}$ & $27.2 \pm 0.3^{\mathrm{ab}}$ & $24.4 \pm 1.1^{\mathrm{b}}$ \\
\hline$\left(a^{*} / b^{*}\right)_{\text {whole }}$ & $1.0 \pm 0.2^{\mathrm{a}}$ & $0.9 \pm 0.03^{\mathrm{a}}$ & $1.1 \pm 0.02^{\mathrm{a}}$ \\
\hline$\left(\mathrm{L}^{*}\right)_{\text {fresh cut }}$ & $45.0 \pm 1.9^{\mathrm{a}}$ & $36.1 \pm 1.9^{\mathrm{b}}$ & $42.9 \pm 1.4^{\mathrm{ab}}$ \\
\hline$\left(a^{*}\right)_{\text {fresh cut }}$ & $32.3 \pm 0.4^{\mathrm{a}}$ & $26.0 \pm 0.5^{\mathrm{b}}$ & $20.5 \pm 0.2^{\mathrm{c}}$ \\
\hline$\left(\mathrm{b}^{*}\right)_{\text {fresh cut }}$ & $28.3 \pm 1.0^{\mathrm{a}}$ & $21.9 \pm 0.3^{\mathrm{b}}$ & $23.6 \pm 0.5^{b}$ \\
\hline$\left(a^{*} / b^{*}\right)_{\text {fresh cut }}$ & $1.1 \pm 0.02^{\mathrm{a}}$ & $1.2 \pm 0.05^{\mathrm{a}}$ & $0.9 \pm 0.01^{\mathrm{b}}$ \\
\hline Weight (g) & $91.7 \pm 0.3^{\mathrm{b}}$ & $104.3 \pm 2.8^{\mathrm{a}}$ & $96.7 \pm 3.5^{b}$ \\
\hline Soluble solids (Brix) & $6.7 \pm 0.02^{\mathrm{a}}$ & $6.6 \pm 0.02^{\mathrm{a}}$ & $5.8 \pm 0.1^{\mathrm{b}}$ \\
\hline Titratable acidity (\% citric acid) & $0.4 \pm 0.3^{\mathrm{a}}$ & $0.40 \pm 0.02^{\mathrm{a}}$ & $0.4 \pm 0.03^{\mathrm{a}}$ \\
\hline
\end{tabular}

$\mathrm{L}^{*}$ is the approximate measure of lightness, $\mathrm{a}^{*}$ takes positive values for reddish colors and negative values for greenish ones, $\mathrm{b}^{*}$ is positive for yellowish color and negative for the bluish. Values represent the mean of three replicates \pm standard deviation. Mean followed by the same superscripts are not significantly different $(\mathrm{P}<0.05)$. 
Table 2 Total carotenoids, lycopene, $\beta$-carotene, total phenolics, flavonoids, ascorbic acid and total vitamin $\mathrm{C}$ content of the studied tomato cultivars.

\begin{tabular}{l|rrrrrrr}
\multicolumn{1}{c|}{ Cultivars } & \multicolumn{1}{c}{ Tc } & \multicolumn{1}{c}{ Ly } & \multicolumn{1}{c}{$\beta$-c } & \multicolumn{1}{c}{ AsA } & Tv C & Tp & Fl \\
\hline HLT-F71 & $165.5 \pm 6.8^{\mathrm{a}}$ & $150.0 \pm 11.0^{\mathrm{a}}$ & $8.7 \pm 2.4^{\mathrm{a}}$ & $174.4 \pm 12.5^{\mathrm{a}}$ & $233.0 \pm 6.5^{\mathrm{b}}$ & $549.7 \pm 33.7^{\mathrm{a}}$ & $323.1 \pm 10.2^{\mathrm{b}}$ \\
HLT-F72 & $125.4 \pm 5.5^{\mathrm{b}}$ & $86.9 \pm 2.0^{\mathrm{b}}$ & $3.3 \pm 1.09^{\mathrm{a}}$ & $193.3 \pm 23.5^{\mathrm{a}}$ & $271.6 \pm 6.0^{\mathrm{a}}$ & $407.0 \pm 12.8^{\mathrm{b}}$ & $450.7 \pm 17.7^{\mathrm{a}}$ \\
\hline Rio Grande & $85.7 \pm 2.4^{\mathrm{c}}$ & $74.8 \pm 1.3^{\mathrm{b}}$ & $4.5 \pm 0.3^{\mathrm{a}}$ & $91.0 \pm 12.34^{\mathrm{b}}$ & $221.8 \pm 5.0^{\mathrm{a}}$ & $421.2 \pm 6.4^{\mathrm{b}}$ & $243.5 \pm 6.7^{\mathrm{c}}$ \\
\hline
\end{tabular}

Tc: Total carotenoids (mg E $\beta$-ca/Kg fw); Ly: Lycopene (mg/kg fw); $\beta$-c: $\beta$-carotene (mg/kg fw); Asa: AsA (mg/kg fw); Tv C: Total vitamin C (mg/kg fw); Tp: Total phenolics (mg EAG/kg fw); Fl: Flavonoid (mg ER/kg fw); Values represent the mean of three replicates \pm standard deviation. Mean followed by the same superscripts are not significantly different $(\mathrm{P}<0.05)$.

Table 3 Hydrophilic and lipophilic antioxidant activity of the studied tomato cultivars determined using the TEAC and the FRAP assays.

\begin{tabular}{l|cccc}
\hline \multirow{2}{*}{ Cultivars } & \multicolumn{2}{c}{ TEAC $^{*}$ assay $(\mu \mathrm{M}$ trolox $/ 100 \mathrm{~g} \mathrm{fw})$} & \multicolumn{2}{c}{ FRAP $^{* *}$ assay $(\mathrm{mM}$ FRAP/g fw) } \\
\cline { 2 - 5 } & HAA & LAA & HAA & $3.2 \pm 0.2^{\mathrm{a}}$ \\
\hline HLT-F71 & $148.0 \pm 8.1^{\mathrm{a}}$ & $258.5 \pm 7.17^{\mathrm{a}}$ & $0.3^{\mathrm{a}}$ \\
HLT-F72 & $119.9 \pm 5.3^{\mathrm{b}}$ & $155.6 \pm 5.35^{\mathrm{b}}$ & $3.1 \pm 0.1^{\mathrm{b}}$ & $2.8 \pm 0.4^{\mathrm{a}}$ \\
Rio Grande & $111.0 \pm 4.6^{\mathrm{b}}$ & $111.99 \pm 4.7^{\mathrm{c}}$ & $1.4 \pm 0.2^{\mathrm{c}}$ & $1.2 \pm 0.2^{\mathrm{b}}$ \\
\hline
\end{tabular}

Values represent the mean of three replicates \pm standard deviation. Mean followed by the same superscripts are not significantly different (P < 0.05$)$. TEAC ${ }^{*}$ : Trolox-equivalent antioxidant capacity; FRAP*: Ferric reducing antioxidant power; HAA: Hydrophilic antioxidant activity; LAA: Lipophilic antioxidant activity.

Table 4 Summary of the functional quality oh high-lycopene tomato as compared to field grown ordinary and highlycopene tomato

\begin{tabular}{l|ccc}
\hline \multicolumn{1}{|c}{ Phytochemicals } & High-lycopene tomato (greenhouse) & High-lycopene tomato (open field) & Ordinary tomato (open field) \\
\hline Total carotenoids & ++ & +++ & + \\
Lycopene & ++ & +++ & + \\
Total phenolics & +++ & ++ & + \\
Flavonoids & +++ & ++ & + \\
Ascorbic acid & ++ & ++ & ++ \\
HAA & ++ & ++ & + \\
LAA & ++ & ++ & + \\
\hline
\end{tabular}

+: Low level; ++: moderate level; +++: High level

Hydrophilic and Lipophilic Antioxidant Activity

The HAA and LAA determined using both TEAC and FRAP assays of ordinary and high-lycopene advanced breeding lines are shown in table 3. The HAA and LAA values measured by both methods were significantly different between the studied tomato cultivars $(\mathrm{P}<0.05)$. Disregarding the analytical method, the highest HAA and LAA values were estimated in HLT-F71 and the lowest were recorded for Rio Grande.

Using the TEAC assay, HAA values ranged from $111.0 \mu \mathrm{M}$ Trolox/100 $\mathrm{g}$ fw in Rio Grande to $148.0 \mu \mathrm{M}$ Trolox/100 $\mathrm{g}$ fw in HLT-F71. HLT-F72 showed similar HAA to Rio Grande. The HAA contributed $36 \%$ to $51 \%$ for the TAA. However, using the FRAP assay, HAA values ranged from 1.4 mM FRAP/ $\mathrm{g}$ fw in Rio Grande to $3.2 \mathrm{mM}$ FRAP/g fw. The HAA was found to contribute $52-57 \%$ to the TAA.

Regarding the LAA, based on the TEAC assay, values ranged from $112.0 \mu \mathrm{M} / 100 \mathrm{~g}$ fw in Rio Grande to 258.5 $\mu \mathrm{M}$ trolox/100 $\mathrm{g} \mathrm{fw}$ in HLT-F71. However, when the FRAP assay was considered, values ranged from $1.2 \mathrm{mM}$ FRAP/g fw in Rio Grande to $3.2 \mathrm{mM}$ FRAP/g fw in HLTF71. HLT-F72 exhibited statistically similar LAA to HLT-F71. This confirms previous works indicating that the FRAP assay is more sensitive to hydrophilic extract since carotenoids had no ferric reducing ability (Goerge et al., 2004; Ilahy et al., 2011a; Lenucci et al., 2006). To our knowledge, this is the first time that the antioxidant activity in the high-lycopene tomato breed lines grown under greenhouse conditions has been reported. Nevertheless, our results are similar to those reported for open-field tomato cultivars carrying high-pigment mutations ranging from 114.4 to $572 \mu \mathrm{M}$ Trolox/100 g fw (Hdider et al., 2013; Ilahy et al., 2011a, b; Ilahy et al., 2016).

Lower values were generally reported for greenhouse tomato cultivars ranging from 087 to $1.24 \mathrm{mM} / 100 \mathrm{~g}$ fw using the FRAP assay (Chandra and Ramalingam 2011) and from 63 to $94 \mu \mathrm{M}$ Trolox/100 $\mathrm{g}$ fw using the TEAC assay (Toor and Savage 2005).

Therefore, the development of high-lycopene tomato cultivars suitable for greenhouse condition will lead to the daily intake not only of lycopene but also of other important bioactive molecules such as polyphenols, flavonoids and ascorbic acid.

The marked decrease in lycopene content (150 mg per $\mathrm{kg} \mathrm{fw}$ ) under greenhouse conditions with respect to fieldgrown high-lycopene tomato attaining $300 \mathrm{mg}$ per $\mathrm{kg} \mathrm{fw}$ was compensated by a huge accumulation of phenolics and flavonoids and similar total vitamin $\mathrm{C}$ content, HAA and LAA compared to field grown high-lycopene tomato (Table 4) . Therefore, the development of high-lycopene tomato cultivars suitable for greenhouse condition will lead to increase the daily intake not only of lycopene but also of other important bioactive molecules such as polyphenols, flavonoids and ascorbic acid. 
Table 5 Pearson's correlation coefficient $(\mathrm{r} \pm \mathrm{SE})$ of phytochemical composition and colour attributes determined in whole and fresh cut tomato fruits

\begin{tabular}{|c|c|c|c|c|c|c|c|c|}
\hline \multirow{2}{*}{ Trait $^{\mathrm{a}}$} & \multicolumn{4}{|c|}{ Whole } & \multicolumn{4}{|c|}{ Fresh cut } \\
\hline & $\mathrm{L}^{*}$ & $a^{*}$ & $\mathrm{~b}^{*}$ & Ratio a*/b* & $\mathrm{L}^{*}$ & $a^{*}$ & $\mathrm{~b}^{*}$ & Ratio $a^{*} / b^{*}$ \\
\hline AsA & $0.82 \pm 0.1^{* * *}$ & $0.23 \pm 0.3^{\mathrm{ns}}$ & $0.67 \pm 0.2^{*}$ & $-0.71 \pm 0.2^{\mathrm{ns}}$ & $-0.18 \pm 0.3^{\mathrm{ns}}$ & $0.69 \pm 0.2^{*}$ & $0.13 \pm 0.3^{\mathrm{ns}}$ & $0.88 \pm 0.1^{* * *}$ \\
\hline VITC & $0.34 \pm 0.3^{\mathrm{ns}}$ & $-0.26 \pm 0.3^{\mathrm{ns}}$ & $0.22 \pm 0.3^{\mathrm{ns}}$ & $-0.38 \pm 0.3^{\text {ns }}$ & $-0.72 \pm 0.2^{*}$ & $0.13 \pm 0.3^{\mathrm{ns}}$ & $-0.53 \pm 0.2^{\mathrm{ns}}$ & $0.71 \pm 0.2^{*}$ \\
\hline ТРH & $0.16 \pm 0.3^{\mathrm{ns}}$ & $0.58 \pm 0.2^{\mathrm{ns}}$ & $0.45 \pm 0.3^{\mathrm{ns}}$ & $-0.11 \pm 0.3^{\mathrm{ns}}$ & $0.50 \pm 0.3^{\mathrm{ns}}$ & $0.75 \pm 0.1^{*}$ & $0.94 \pm 0.04^{* *}$ & $0.19 \pm 0.3^{\mathrm{ns}}$ \\
\hline FLAV & $0.55 \pm 0.2^{\mathrm{ns}}$ & $-0.05 \pm 0.3^{\mathrm{ns}}$ & $0.32 \pm 0.3^{\mathrm{ns}}$ & $-0.40 \pm 0.3^{\mathrm{ns}}$ & $-0.65 \pm 0.2^{\mathrm{ns}}$ & $0.34 \pm 0.3^{\mathrm{ns}}$ & $0.32 \pm 0.3^{\mathrm{ns}}$ & $0.82 \pm 0.1^{* * *}$ \\
\hline $\mathrm{HAA}^{\mathrm{TEAC}}$ & $0.30 \pm 0.3^{\mathrm{ns}}$ & $0.16 \pm 0.3^{\text {ns }}$ & $0.64 \pm 0.2^{\mathrm{ns}}$ & $-0.44 \pm 0.2^{\mathrm{ns}}$ & $0.42 \pm 0.3^{\text {ns }}$ & $0.68 \pm 0.2^{*}$ & $0.64 \pm 0.2^{\mathrm{ns}}$ & $0.36 \pm 0.3^{\text {ns }}$ \\
\hline $\mathrm{HAA}^{\text {FRAP }}$ & $0.60 \pm 0.2^{\mathrm{ns}}$ & $0.39 \pm 0.3^{\mathrm{ns}}$ & $0.77 \pm 0.1^{*}$ & $-0.53 \pm 0.3^{\mathrm{ns}}$ & $0.03 \pm 0.3^{\mathrm{ns}}$ & $0.96 \pm 0.02^{* *}$ & $0.57 \pm 0.2^{\mathrm{ns}}$ & $0.83 \pm 0.1^{* * *}$ \\
\hline TCAR & $0.50 \pm 0.2^{\mathrm{ns}}$ & $0.40 \pm 0.3^{\text {ns }}$ & $0.69 \pm 0.2^{*}$ & $-0.44 \pm 0.3^{\mathrm{ns}}$ & $0.11 \pm 0.3^{\mathrm{ns}}$ & $0.94 \pm 0.04^{* *}$ & $0.62 \pm 0.2^{\mathrm{ns}}$ & $0.77 \pm 0.1^{*}$ \\
\hline LYCO & $0.49 \pm 0.2^{\mathrm{ns}}$ & $0.42 \pm 0.3^{\mathrm{ns}}$ & $0.70 \pm 0.2^{*}$ & $-0.39 \pm 0.3^{\mathrm{ns}}$ & $0.48 \pm 0.3^{\mathrm{ns}}$ & $0.89 \pm 0.07^{* *}$ & $0.76 \pm 0.1^{*}$ & $0.53 \pm 0.2^{\mathrm{ns}}$ \\
\hline BET & $-0.10 \pm 0.3^{\mathrm{ns}}$ & $0.40 \pm 0.3^{\mathrm{ns}}$ & $0.26 \pm 0.3^{\mathrm{ns}}$ & $-0.03 \pm 0.3^{\mathrm{ns}}$ & $0.31 \pm 0.3^{\mathrm{ns}}$ & $0.57 \pm 0.2^{\mathrm{ns}}$ & $0.85 \pm 0.1^{* *}$ & $0.02 \pm 0.4^{\mathrm{ns}}$ \\
\hline $\mathrm{LAA}^{\mathrm{TEAC}}$ & $0.56 \pm 0.2^{\mathrm{ns}}$ & $0.49 \pm 0.3^{\mathrm{ns}}$ & $0.74 \pm 0.1^{*}$ & $-0.42 \pm 0.3^{\mathrm{ns}}$ & $0.38 \pm 0.3^{\mathrm{ns}}$ & $0.97 \pm 0.02^{* *}$ & $0.77 \pm 0.1^{*}$ & $0.65 \pm 0.2^{\mathrm{ns}}$ \\
\hline $\mathrm{LAA}^{\mathrm{FRAP}}$ & $0.57 \pm 0.2^{\mathrm{ns}}$ & $0.46 \pm 0.3^{\mathrm{ns}}$ & $0.60 \pm 0.2^{\mathrm{ns}}$ & $-0.33 \pm 0.3^{\mathrm{ns}}$ & $-0.03 \pm 0.3^{\mathrm{ns}}$ & $0.87 \pm 0.08^{* *}$ & $0.49 \pm 0.3^{\mathrm{ns}}$ & $0.79 \pm 0.1^{*}$ \\
\hline
\end{tabular}

${ }^{\mathrm{a}} \mathrm{AsA}=$ Ascorbic acid, VITC $=$ Total vitamin $\mathrm{C}, \mathrm{TPH}=$ total phenolics, FLAV = flavonoids, HAA ${ }^{\text {TEAC }}=$ hydrophilic antioxidant activity determined using the TEAC assay, HAA ${ }^{\text {FRAP }}=$ hydrophilic antioxidant activity determined using the FRAP assay, TCAR = total carotenoids, LYCO= lycopene,

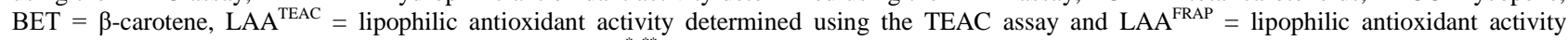
determined using the FRAP assay. ${ }^{\mathrm{ns}}=$ non significant and ${ }^{* * *}=$ significant at $\mathrm{P}<0.05$ or 0.01 , respectively

\section{Correlations}

Correlation between $\mathrm{L}^{*}, \mathrm{a}^{*}$ and $\mathrm{b}^{*}$ colour readings as determined in whole and fresh cut tomato fruit with the phytochemical content and antioxidant activity in both hydrophilic and lipophilic fraction determined using the TEAC assay are reported in table 5.

When data from whole tomato fruit were considered, the colour index $\mathrm{L}^{*}$ was only significantly correlated $(\mathrm{r}=$ $0.82, \mathrm{P}<0.01)$ to the AsA content. The colour index $\mathrm{b}$ was significantly correlated to the content of various phytochemicals including AsA $(\mathrm{r}=0.67, \mathrm{P}<0.05)$, lycopene $(\mathrm{r}=0.70, \mathrm{P}<0.05)$, total carotenoids $(\mathrm{r}=0.69$, $\mathrm{P}<0.05)$ as well as the HAA measured using the FRAP assay $(\mathrm{r}=0.77, \mathrm{P}<0.05)$ and the LAA measured using the TEAC assay $(\mathrm{r}=0.74, \mathrm{P}<0.05)$. No correlations were found with the colour index $\mathrm{a}^{*}$ or the calculated coefficient $\mathrm{a}^{*} / \mathrm{b}^{*}$.

When data from fresh cut tomato fruits was considered, the colour index $\mathrm{L}^{*}$ was significantly correlated $(\mathrm{r}=-0.72, \mathrm{P}<0.05)$ to total vitamin $\mathrm{C}$ content. The colour index $\mathrm{a}^{*}$ was significantly correlated to the contents of both AsA $(\mathrm{r}=0.69, \mathrm{P}<0.05)$ and total phenolics $(\mathrm{r}=0.75, \mathrm{P}<0.05)$ and to HAA values measured using the TEAC assay $(\mathrm{r}=0.68, \mathrm{P}<0.05)$. Highly significant correlations were obtained between $\mathrm{a}^{*}$ and HAA measured using the FRAP assay $(\mathrm{r}=0.96, \mathrm{P}<0.01)$, total carotenoids $(\mathrm{r}=0.94, \mathrm{P}<0.01)$; lycopene content $(\mathrm{r}=$ $0.89, \mathrm{P}<0.01)$ and the LAA measured using both the TEAC $(r=0.97, \mathrm{P}<0.01)$ and FRAP $(\mathrm{r}=0.87, \mathrm{P}<0.01)$ assays. Therefore, based on the redness $\mathrm{a}^{*}$ it is possible to estimate accurately total carotenoids and lycopene contents as well as the LAA determined by both the TEAC and the FRAP assays and the HAA measured by FRAP assay in fresh-cut high-lycopene tomato berries. Using the yellowness index $\mathrm{b}^{*}$, it is possible also to estimate accurately the content of total phenolics and $\beta$ carotene in fresh cut tomato fruits. However, the calculated ratio $\mathrm{a}^{*} / \mathrm{b}^{*}$ can estimate accurately AsA, flavonoids and the HAA measured using the FRAP assay. To our knowledge, this is the first time that colour attributes were determined and related to phytochemical content in high-lycopene tomato berries, Nevertheless, various authors focused on lycopene content found that the higher the ratio of $a^{*} / b^{*}$ or $\left(a^{*} / b^{*}\right)^{2}$ the higher was the lycopene content (Kaur et al., 2013; D'Souza et al., 1992; Ilahy et al., 2005; Brandt et al., 2006).

\section{Conclusions}

The newly developed high-lycopene tomato lines show consistent functional quality attributes in terms of their antioxidant profile and antioxidant activity. This unexploited variability offers an opportunity in breeding programs to improve the functional quality of greenhouse tomato cultivars by developing semi-determinate growth habit varieties for example. Non-destructive measurements of color attributes $\mathrm{L}^{*}, \mathrm{a}^{*}, \mathrm{~b}^{*}$ or the ratio $\mathrm{a}^{*} / \mathrm{b}^{*}$ can be used to accurately estimate not only lycopene content but also the antioxidant composition and antioxidant activity.

\section{References}

Andrews PK, Fahy DA, Foyer C. 2004. Relation between fruit exocarp antioxidants in the tomato (lycopersicon esculentum) high-pigment-1 mutant during development. Physiologiae planatarum. 120: 519-528.

Arias R, Lee TC, Logendra L, Janes H. 2000. Correlation of lycopene measured by HPLC with the L, a, b, color readings of hydroponic tomato and the relationship of maturity with color and lycopene content. Journal of Agricultural Food Chemistry. 48 (5): 1697-1702.

Asami Dk, Hong YJ, Barrett DM, Mitchell AE. 2003. Comparison of the Total Phenolic and Ascorbic Acid Content of FreezeDried and Air-Dried Marionberry, Strawberry, and Corn Grown Using Conventional, Organic, and Sustainable Agricultural Practices, J Journal of Agricultural Food Chemistry. 51:12371241.

Benzie IEF, Strain JJ. 1996. The ferric reducing ability of plasma (FRAP) as a measure of antioxidant power: the FRAP assay. Analytical Biochemistry. 239: 70-76.

Bino RJ, De Vos CHR, Lieberman,M, Hall RD, Bovy A, Jonker HH, Tikunov Y, Lommen A, Moco S, Levin I. 2005. The lighthyperresponsive high pigment-2 ${ }^{d g}$ mutation of tomato: alterations in the fruit metabolome. New Phytologist. 166 (2): 427-438. 
Bramley PM. 2000. Is lycopene beneficial to human health? Phytochemistry. 54: 233-236.

Brandt S, Pék Z, Barna E, Lugasi A, Helyes L. 2006. Lycopene content and colour of ripening tomatoes as affected by environmental conditions. Journal of the Science of Food and Agriculture 86: 568-572.

Chandra HM, Shanmugaraj BM, Srinivasan B, Ramalingam S. 2012. Influence of genotypic variations on antioxidant properties in different fractions of tomato. Journal of Food Science. 77 (11): 1174-1178.

Chandra HM, Ramalingam,S. 2011. Antioxidant potentials of peel, pulp, and seed fractions of commercially important tomato cultivars. Food Science Biotechnology. 20: 15-21

D’Souza MC, Singha S, Ingle M. 1992. Lycopene concentration of tomato fruit can be estimated from chromaticity values. HortScience. 27 (5): 465-466.

Di Mascio P, Kaiser S, Sies H. 1989. Lycopene as the most efficient biological carotenoid singlet oxygen quencher. Archives of Biochemistry and Biophysics. 274: 532-538.

Erdman JW, Ford NA, Lindshield BL. 2009. Are the health attributes of lycopene related to its antioxidant function? Archives of BiochemIstry and Biophysics. 483: 229-235.

Fernández-García E. 2014. Photoprotection of human dermal fibroblasts against ultraviolet light by antioxidant combinations present in tomato. Food and Function. 5: 285-290.

Fernández-García E. 2014. Skin protection against UV-light by dietary antioxidants. Food and Function 5: 1994-2003.

Fernàndez-Ruiz V, Torreccila JS, Cámara $\mathrm{M}$, Sánchez Mata MC, Shoemaker C. 2010. Radial basis network analysis of color parameters to estimate lycopene content on tomato fruits. Talanta. 83: 9-13.

Fish WW, Perkins-Veazie P, Collins JK. 2002. A quantitative assay for lycopene that utilizes reduced volumes of organic solvents. Journal of Food Composition and Analysis. 15: 309-17.

Galpaz N, Wang Q, Menda N, Zamir D, Hirschberg J. 2008. Abscisic acid deficiency in the tomato mutant high-pigment 3 leading to increased plastid number and higher fruit lycopene content. The Plant Journal. 53: 717-730.

George B, Kaur C, Khurdiya DS, Kapoor HC. 2004. Antioxidants in tomato (Lycopersicon esculentum) as a function of genotype. Food Chemistry. 84: 45-51.

Hdider C, Ilahy R, Tlili I. 2013. Evaluation of the antioxidant activity in different Citrus cultivars grown in Tunisia. In: Ilahy R (Ed) Tunisian Fruits and Vegetables.Food 7. (Special Issue 1): 44-46.

Ilahy R, Hdider C. 2007. Effect of ripening stage on lycopene content of different processing tomato cultivars grown in Tunisia. Acta. Horticulturae (ISHS). 758: 185-190.

Ilahy R, Piro G, Tlili I, Riahi A, Rabaoui S, Ouerghi I, Hdider C, Lenucci MS. 2016. Fractionate analysis of the phytochemical composition and antioxidant activities in advanced breeding lines of high-lycopene tomatoes. Food and Function. 7: 574583.

Ilahy R, Riahi A, Tlili I, Hdider C, Lenucci MS, Dalessandro G. 2015 .Carotenoid content in intact plastids isolated from ordinary and high-lycopene tomato (Solanum lycopersicum L.) cultivars. Acta. Horticulturae (ISHS). 1081: 135-140.

Ilahy R, Hdider C, Tlili I. 2009. Bioactive compounds and antioxidant activity of tomato high-lycopene content advanced breeding lines. The African Journal of Plant Science and Biotechnology3(SI1),1-6.

Ilahy R, Hdider C, Lenucci MS, Tlili I, Dalessandro G. 2011a. Antioxidant activity and bioactive compound changes during fruit ripening of high-lycopene tomato cultivars. Journal of Food Composition and Analysis. 24:588-595.

Ilahy R, Hdider C, Lenucci MS, Tlili I, Dalessandro G. 2011 b. Phytochemical composition and antioxidant activity of highlycopene content tomato (Lycopersicon esculentum Mill) cultivars grown southern Italy. Scientia Horticulturae. 127 (3): 255-261.
Kampfenkel K, Van Montagu M, Inzè D. 1995. Extraction and determination of ascorbate and dehydroascorbate from plant tissue. Analytical Biochemistry. 225: 165-167.

Kaur C, Walia S, Nagal S, Walia S, Singh J, Singh BB, Saha S, Singh B, Kalia P, Jaggi S, Sarika. 2013. Functional quality and antioxidant composition of selected tomato (Solanum lycopersicon L) cultivars grown northern India. LWT-Food Science and Technology. 50: 139-145.

Lee HS. 2001. Characterization of carotenoids in juice of red navel orange (Cara Cara). Journal of Agricultural and Food Chemistry. 49: 2563-2568.

Lenucci MS, Cadinu D, Taurino M, Piro G, Giuseppe D. 2006. Antioxidant composition in cherry and high-pigment tomato cultivars. Journal of Agricultural Food and Chemistry. 54: 2606-2613.

Lenucci MS, Serrone L, De Caroli M, Fraser PD, Bramley P, Piro G, Dalessandro G. 2012. Isoprenoid, lipid, and protein contents in intact plastids isolated from mesocarp cells of traditional and high-pigment tomato cultivars at different ripening stages. Journal of Agricultural Food and Chemistry. 60: 1764-1775.

Levin I, De Vos CHR, Tadmor Y, Bovy A, Liberman M, OrenShamir M. 2006. High-pigment tomato mutants- more than just lycopene (a review). Israel Journal of Plant Sciences. 54: 179190.

Martínez-Valverde I, Periago MJ, ProvanG, Chesson A. 2002. Phenolic compounds, lycopene and antioxidant activity in commercial varieties of tomato (Lycopersicon esculentum). Journal of the Science of Food and Agriculture. 82: 323-330.

Miller NJ, Rice-Evans CA. 1997. The relative contribution of ascorbic acid and phenolic antioxidants to the total antioxidant activity of orange and apples fruits juices and blackcurrant drinks. Food Chemistry. 60 (3): 331-337.

Mochizuki T, Kamimura S. 1984. Inheritance of vitamin C content and its relation to other characters in crosses between $h p$ and $o g$ varieties of tomatoes. In $9^{\text {th }}$ Meeting of the EUCARPIA Tomato Workshop, Wageningen, The Netherlands; EUCARPIA Tomato Working Group: Wageningen, The Netherlands, 8-13

Mustilli AC, Fenzi F, Gliento R, Alfano F, Bowler, C. 1999. Phenotype of the tomato high pigment- 2 mutant is caused by a mutation in the tomato homologue of de-etiolated 1. the Plant Cell. 11: 145-157.

Nagata M, Yamashita I. 1992. Simple method for simultaneous determination of chlorophyll and carotenoids in tomato fruit. Nippon Shokuhin Kogyo Gakkaish, 39(10): 925-928.

Pellegrini N, Colombi B, Salvatore S, Brenna O, Galaverna G, Del Rio D, 2007. Evaluation of antioxidant capacity of some fruit and vegetable foods: Efficiency of extraction of a sequence of solvents. Journal of the Science of Food and Agriculture. 87: 103-111.

Phillips KM, Tarrgó-Trani MT, Gebhardt SE, Exler J, Patterson KY., Haytowitz, DB, Pehrsson PR, Holden JM. 2010. Stability of vitamin $\mathrm{C}$ in frozen raw fruit and vegetable homogenates Journal of Food Composition and Analysis. 23: 253-259.

Qu M, Nan X, Gao Z, Guo B, Liu B, Chen Z. 2013 Protective effects of lycopene against methylmercury-induced neurotoxicity in cultured rat cerebellar granule neurons. Brain Research. 1540: 92-102.

Rice-Evans C.A, Sampson J, Bramley PM, Holloway DE. 1997. Why do we expect carotenoids to be antioxidants in vivo? Free Radical Research. 26: 381-98.

Siddiqui, MW, Chakraborty I, Mishra P, Hazra P. 2014. Bioactive attributes of tomato possessing dg, ogc and rin genes. Food and Function. 5, 936-943.

Soares NCP, Teodoro AJ, Oliveira FL, Takiya CM, Junior AP, Nasciutti LE, Lotsch PF, Granjeiro JM, Ferreira, LB, Pereira Gimba ER., Borojevic R. 2014. Lycopene induce apoptosis in human prostate cells and alters the expression of Bax and Bcl-2 genes. LWT- Food Science and Technology. 59: 1290-1297.

Spanos GA, Wrolstad RE. 1990. Influence of processing and storage on the phenolic composition of Thompson Seedless grape juice. Journal of Agricultural Food and Chemistry. 38: 1565-1571. 
Takashima M, Shichiri M, Hagihara Y, Yoshida Y, Niki E. 2012. Capacity of peroxyl radical scavenging and inhibition of lipid peroxidation by $\beta$-carotene, lycopene, and commercial tomato juice. Food and Function 3 (11): 1153-1160.

Thaipong K, Boonprakob U, Crosby K, Cisneros-Zevallos L, Byrbe DH. 2006. Compraison of ABTS, DPPH, FRAP and ORAC assays for estimating antioxidant activity from guava fruit extracts. Joural of Food ComposItion and Analysis. 19: 669657.

Toor RK, Savage GP. 2005. Antioxidant activity in different fraction of tomatoes. Food Research International. 38: 487-494.
Vínha AF, Alves RC, Barreira SVP, Castro A, Costa ASG, Betriz M, Oliveira, PP. 2014. Effect of peel and seed removal on the nutritional value and antioxidant activity of tomato (Lycopersicon esculentum L.) fruits. LWT-Food Science and Technology. 55: 197-202.

Wann EV. 1997. Tomato germplasm lines T4065, T4099, T5019, and T5020 with unique genotypes that enhance fruit quality. Horticultural Science. 32, 747-748.

Zhishen J, Mengcheng T, Jianming W. 1999. The determination of flavonoid contents in mulberry and their scavenging effects on superoxide radicals. Food Chemistry. 64 (4), 555-559. 